\title{
EFFICIENT CONSUMER RESPONSE (ECR): A SURVEY OF THE AUSTRALIAN GROCERY INDUSTRY
}

\author{
John K. Harris \\ Paula M.C. Swatman \\ Electronic Commerce Research Group \\ Department of Information Systems \\ Monash University \\ E-mail: paula.swatman@is.monash.edu.au
}

\begin{abstract}
Efficient consumer response (ECR) is a U.S. supply chain management strategy which attempts to address the inefficiencies which have led to excessive inventory and unnecessary costs at all levels within the grocery industry supply chain. This paper discusses the traditional grocery store format, the supermarket, and the ways in which inefficient business practices developed in the U.S. grocery supply chain; and discusses the major business activities needed for successful implementation of ECR. The paper then presents a brief summary of the results of a survey of ECR knowledge and usage within the Australian grocery industry, which is the initial phase of a long term research project whose main purpose is to evaluate ECR as it applies to that industry.
\end{abstract}

\section{Keywords}

Food industry, efficient consumer response, supply chain management, exploratory research, strategic IS, strategic alliances, business process re-engineering.

\section{INTRODUCTION}

Efficient Consumer Response (ECR) originated in the United States in 1992 as a direct result of threats from alternative store 'formats' (or types) and their supply chains (McKinsey \& Co. 1992) which highlighted major inefficiencies within the traditional grocery store format, the supermarket, and its supply chain (Kurt Salmon Associates 1993). The concept on which ECR is based originated from the quick response (QR) strategy already existing in the textile and apparel industries (Cooke 1994) which, in turn, were based on the manufacturing justin-time (JT) concept (Ellram, La Londe and Weber 1989; Knill 1990).

ECR is concerned with changing, or reengineering, the grocery supply chain from a 'push system' to a 'pull system' - where trading partners form new alliance relationships and the replenishment of store products is initiated by the point of sale (POS) data. The JIT concept was simple: to deliver raw material to production areas in the exact required amount at the precise time it was needed. The use of raw material pulls new raw material into the production process. During the mid 1980s the JT manufacturing concept was applied to the U.S. textile and apparel industries in an attempt to combat market penetration by overseas manufacturers. This textile and apparel industries initiative was termed 'quick response' and attempted to reduce the amount of inventory held within the apparel supply chain. Quick response required the retailer to share point-of-sale-scanned data with manufacturers to improve the flow of product through the supply chain. The grocery industry noted the success of the quick response approach to managing supply chain data and proposed a similar stock replenishment system called ECR (Cooke 1994; Ellram, La Londe and Weber 1989).

\section{GROCERY INDUSTRY}

\section{Supply Chain Practices and the Implications of Inefriciency}

The traditional grocery retail store, the supermarket, developed during the 1920's in the U.S. The supermarket is a large, departmentalised retail store (Pintel and Diamond 1991) which operates on a self serve basis - selling primarily grocery products and, occasionally, a small assortment of non-grocery merchandise. During the 1930's supermarkets experienced explosive growth due to the economic depression and the mobility provided by the automobile - consumers were no longer restricted to using the local, limited-line food store, but could travel to more distant but cheaper supermarkets (Hayward and York 1976). The supermarket with its high operating efficiencies quickly became the popular and dominant retail grocery format, deposing the (limited line) food store by selling goods at lower prices (Morgenstein and Strongin 1992). During the 1940's and 1950's the supermarket became the major food distribution channel in the U.S.

During the 1950 s the U.S. became saturated with supermarkets, which led to the development of innovative ways to maintain profits. These included the use of private brand labels, stamps and games. Large supermarket chain stores were the primary initiators of private brand labels as they were able to reduce product, distribution and selling costs to such an extent that these products could be sold at a considerable discount to consumers and still 
return a greater profit to the retailer (National Commission of Food Marketing 1971). Stamps were issued to customers in amounts based on the volume of grocery purchases. The collection of a suitable number of stamps could then be exchanged for a variety of products such as household goods, toys and recreation equipment (Mayo 1993). The use of games was introduced during the early 1960s by supermarket chains in an attempt to build consumer loyalty by encouraging shoppers to purchase more regularly from the same store to increase their chance of winning a prize. Consumers were given free game slips based on the purchase value at the check-out station (Allvine 1971).

Discounting, based on low price and high-pressure advertising, began replacing the use of stamps and games as a promotional tool during the 1970s. It is estimated that such consumer promotional activities added as much as $4 \%$ to the costs of food items and as much as $20 \%$ to the overhead costs of operating a supermarket (Mayo 1993). Other supermarkets discounted a large number of well known leading items in an attempt to attract customers to the store, who would then purchase other non-discount items or buy items on impulse. Discounting resulted in larger and larger physical store sizes, as profits accrued only through huge volume, frequent sales (Forbes magazine 1971). To attract additional higher sales the discount supermarket added additional or larger departments such as pharmacy, bakery and general merchandise in an attempt to create a one-stop-shopping store.

During this same period supermarket operators began using hard-hitting newspaper advertisements with pricing comparisons and shopper testimonials. These advertisements would often include coupons - which could be used either by manufacturers to boost the sale of a particular product, or by retailers to improve sales of a particular product within a particular store. The presentation of the coupon by the consumer at the supermarket checkout results in a discount for the coupon item being purchased (Peak and Peak 1977). Couponing has remained the most prevalent form of consumer promotion in the U.S. grocery industry today, although the use of stamps and games as a consumer promotional tool has almost disappeared. Couponing is highly paper intensive and costly to administer, with only around $2.6 \%$ of coupons being redeemed annually (Kurt Salmon Associates 1993). Despite its continued use, the coupon is thus considered an inefficient promotional tool.

Changes in demographic patterns caused a slowing of overall U.S. grocery sales during the 1970s and 1980s: population growth decelerated, following the post-war boom; increasing numbers of consumers began to eat out and, in consequence, spent less of their disposable incomes on food prepared and eaten at home (Garry 1995; Sansolo 1994); and alternative store formats began to market grocery items aggressively in new ways (Newton 1993). At the same time, grocery industry organisations sought to increase their profits at the expense of their supply chain trading partners, leading to adversarial relationships between sellers and buyers (Michelson 1995). The complexity of deals between grocery trading partners and the performance measurement systems used led to large inventory hodlings throughout the supply chain, with sellers (manufacturers, distributors and/or brokers) continually offering deals to buyers (wholesales, distributors, brokers and/or retailers) to 'push' products into the supply chain (Sansolo and Garry 1992; Schlossberg 1992; Teinowitz 1993).

In most transactions, the seller is trying to sell as much as possible at the highest possible price, while the buyer is trying to buy only what is needed as cheaply as possible (Liesse 1994); rather than developing trading partner relationships based on mutual benefit. The traditional key performance measurement systems used for selling and buying fuelled these adversarial relationships, since the measurement system for the seller was sales and shipments and that for the buyer was gross margins (Hastings 1994). The sellers would start with very high selling prices which would later be discounted for trade promotional activities or to meet selling objectives within a given time period. Buyers would seek to increase their gross margins by buying additional inventory during the discount period and selling at regular prices after the discount period had ended ('investment' or 'forward' buying) or by re-selling it immediately at a profit to buyers in other regions which had not been offered the discount (known as 'diverting') (Harding 1995).

As forward buying and diverting became more widespread, sellers (particularly manufacturers) realised that a growing proportion of their trade promotion spending was not reaching the consumer in the way of reduced prices, but instead was subsidising the buyer's business operation. Sellers, in an attempt to force buyers to pass on the savings offered by trade promotions to the consumers, continued to offer more and more complex deals (Kurt Salmon Associates 1993). It was the complexity of these deals between grocery trading partners which led to excessive inventory throughout the supply chain, with suppliers continually offering deals to wholesalers/distributors and/or retailers to 'push' products into the supply chain (Schlossberg 1992; Teinowitz 1993).

While margins remained high, supermarket operators tolerated these inefficient practices - despite their tendency to create increased transportation, administration and warehousing costs. But as more and more of the U.S. grocery supply chain engaged in complex deals, forward buying, diverting and promotional activities, any real competitive advantage which might have existed originally was lost, although the additional costs continued (and increased). It was clear that a more efficient means of moving goods through the supply chain was needed - in particular, one which would encourage the growth of improved trading partner relationships, while 
reducing inventory holdings.

\section{Efficient Consumer Response}

ECR calls for the creation of a timely, accurate and paperless flow of information - relying heavily on Electronic Data Interchange (EDI) and strategic alliances between supply chain members (Sansolo 1993). The goal of ECR is to take out of the supply chain costs which do not add consumer value (Robins 1994). ECR is about producing efficiencies in the grocery supply chain within the four core business process areas of efficient store assortment, efficient replenishment, efficient promotions and efficient product introductions (Kurt Salmon Associates 1993).

\section{ECR Business Activities/Initiatives}

To achieve these four efficiencies, ECR requires the following major business activities or initiatives (deRoulet 1993):

(a) continuous replenishment program (CRP);

(b) computer assisted ordering (CAO);

(c) flow-through distribution (cross-docking);

(d) activity-based costing (ABC);

(e) category management;

(f) integrated Electronic Data Interchange (EDI).

\section{(a) Continuous Replenishment Program (CRP)}

Continuous replenishment, usually managed by the manufacturer, is a program used to control and monitor the movement of goods from the manufacturer to the warehouse/distributor (Garry 1994c). CRP involves the manufacturer (rather than the retailer's warehouse) taking responsibility for replenishing the warehouse inventory, with the buyer supplying actual warehouse inventory withdrawal data and data on 'stock-keeping units'(individual line items) to the manufacturer (Cross 1993). CRP programs reduce costs in distributors' inventory, but can increase some costs, such as transportation costs, if the manufacturer ships smaller truck loads more frequently (Garry 1994b). Successful CRP implementation is dependent on effective trade relations, requiring shared business practices and information systems which rely heavily on EDI.

\section{(b) Computer-assisted ordering (CAO)}

Computer-assisted ordering, also known as 'computer-aided ordering' (Fensholt 1992; Garry 1992; Thayer 1991; Weinstein 1995), covers the second half of the overall inventory supply chain - the movement of goods from the warehouse/distribution centre to the retail store. The aim of CAO is to generate store replenishment orders automatically, with minimal management intervention, based on such things as current and historical PoS scan data, delivery data and sales forecasts. The benefits of CAO have been identified as labour savings and dependability, warehouse and shipping improvements, and inventory reduction (Garry 1994c). Traditionally, stores have based their orders on the re-order clerk manually inspecting the store shelves and scanning the shelftag bar codes for those items with limited stock on the shelf (Anderson 1996). The re-order amount entered by the clerk is based on the actual shelf amount and the ideal shelf quantity. The re-order clerk is not in a position to take into account $\mathrm{PoS}$ data, inventory which has already been scheduled for delivery, or likely future trends based on forecasting. Integrated CAO systems are designed to minimise (and even eliminate) these problems.

\section{(c) Flow Through Distribution (cross-docking)}

According to Garry (1994a) the purpose of flow through distribution is to hasten the flow of products from the supplier to the retail store by reducing storage and handling of products at the distribution centre or warehouse. It involves the breaking down of pallets at the distribution centre, reassembling them for store delivery and then shipping them to the retail store without ever storing the product in the warehouse. This requires significant investment in technologies such as EDI, bar coding and scanning of pallets. and cases; and warehouse design changes such as lower ceilings and less racking. The key EDI transaction required for cross-docking is the Advanced Shipping Notice (ASN), to inform the distributor of the merchandise that is about to arrive. The automation of the warehouse inventory management system using bar codes means that these inaccuracies can be eliminated. 


\section{(d) Activity-Based Costing (ABC)}

Activity-based costing provides the cost and operating information necessary to support innovative management improvement initiatives such as ECR. The focus of $A B C$ is on accurate information about the true cost of products, services, processes, activities, distribution channels, customer segments, contracts and projects (Miller 1996). ABC supplies information about profits (where the money is being made) rather than about costs. Traditional accounting systems use gross margin calculations that spread operating costs across all products based on unit purchase price regardless of the actual value chain (Porter 1985) the product passes through. ABC focuses management's attention on controlling the source of costs, decisions that create activities, rather than squeezing budgets. Therefore $A B C$ as part of ECR can increase the profitability of the supply chain by removing or reducing those cost activities that do not add value. This can not be done with traditional systems because they do not reflect costs accurately (Weinstein 1993).

\section{(e) Category Management}

The term category management first appeared in 1987 (Smith 1993) when certain organisations, such as Procter and Gamble (Mathews 1995a), began moving from 'brand' management to management 'by category'. Category management has evolved to mean a process that involves managing product categories as business units and customising them on a store-by-store basis to satisfy consumer demands (Gnau, Richardson and Dippold 1992). A category is a group of products having a common consumer end use (Hofler 1996) and include such things as household cleaners, dairy and frozen foods, paper products, health and beauty care products, soft drinks, etc. Category management allows the category manager to operate a category like a business so as to identify optimal product mix; and to stock each store with specific products that demographic and PoS information indicate customers wish to purchase.

\section{(f) Integrated Electronic Data Interchange (EDI)}

Electronic Data Interchange is the computer-application to computer-application communication of structured, formatted messages based on international standards, using electronic transmission media with no manual intervention (Brawn 1989; Swatman 1993). EDI is a technology which allows structured information to be shared among organisations in the supply chain resulting in significant reductions in transaction costs and enabling the organisations to adopt new and more effective and efficient business strategies (Emmelhainz 1990; Gilmour 1993; Klima 1993; Spence 1994), such as ECR. EDI is viewed as the essential effective enabler of the ECR management strategy because it focuses on achieving integration across organisational functions and between organisations (Swatman 1993) in the grocery supply chain.

\section{AN AUSTRALIAN ECR SURVEY}

At the start of this research project, little U.S. and almost no Australian research into ECR could be discovered. We identified three academic research projects on ECR or continuous replenishment (Hoban 1993; Clark 1994; Mathews 1995) in the U.S. and in Australia we found only a single industry report undertaken for the Grocery Manufacturers of Australia by Coopers \& Lybrand in 1995 . We therefore decided to commence the overall research project (which involves a number of researchers and is expected to take several years) by investigating Australian attitudes to ECR and existing practices by members of the grocery industry in this country - an investigation whicih we believed was most appropriately addressed by means of a mail survey.

Participants were chosen from those organisations directly involved in the grocery supply industry and which considered themselves to be members of the grocery supply chain. The questionnaire was posted to the most senior executive of 1500 grocery industry supply chain members, whose mailing lists were obtained from grocery industry journals (Retail World Pty Ltd 1995; White, Craig, Wiland et al. 1995); and an effective response rate of $30 \%$, or $\mathbf{4 5 0}$ organisations, was obtained after two mailouts of the questionnaire.

The research question under examination was "can Australian grocery industry supply chain members beefit from the efficient consumer response supply chain management strategy"? Industry supply chain members were surveyed to:

- determine the extent of inefficient business practices;

- identify the current use of business activities (supply chain initiatives) necessary for the adoption of the ECR strategy;

- identify those organisations that are aware of the ECR strategy to discover whether their 
organisation (and the supply chain as a whole) can benefit from the ECR strategy;

determine the reasons for adopting ECR by those organisations which have decided to pursue such a strategy.

\section{Inefficient Business Practices}

Figure 1 shows that 'diverting' is little used within the Australian grocery industry, as just $17 \%$ of survey respondents indicated that they use some form of diverting, and only $2 \%$ stated that they used this practice the majority of the time. Deal selling/buying which results in forward buying, however, is prevalent within Australia and, as a result, there are likely to be excessive inventory holdings throughout the Australian grocery supply chain. Despite the greater than optimal inventory holdings, these figures suggest that inefficient promotional activities are used to a much lesser extent than in the U.S. and are therefore far less important as a motivator for ECR in this country.
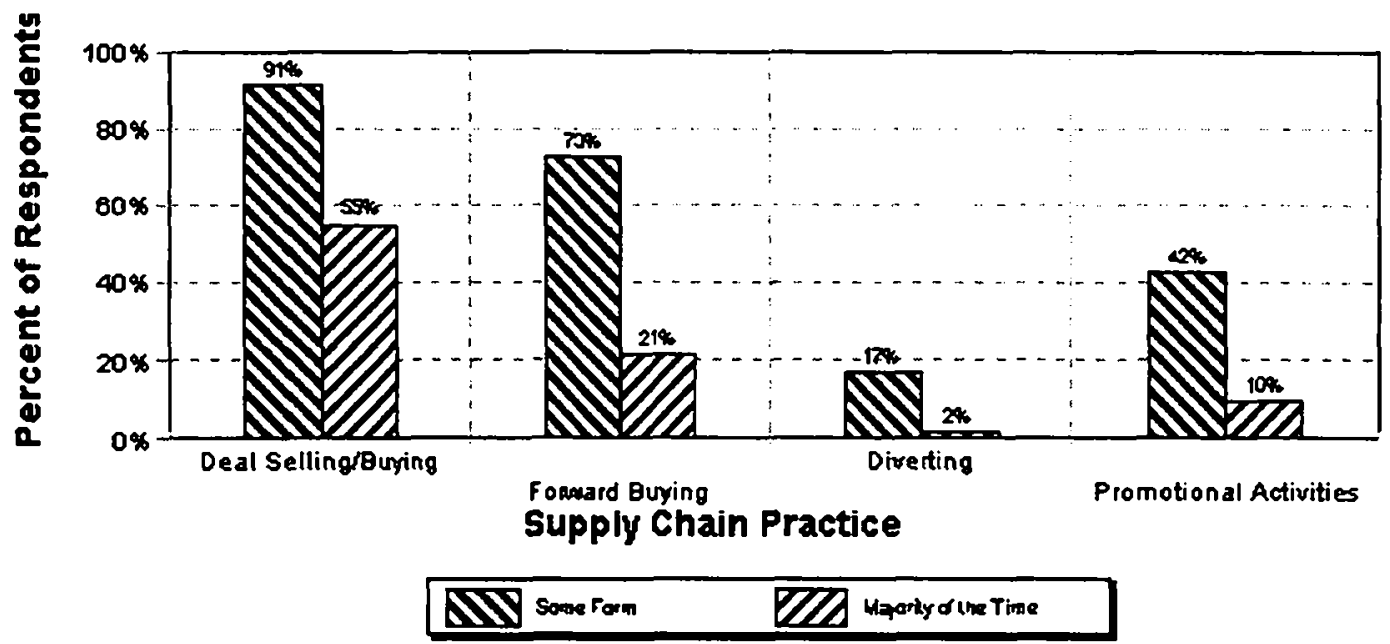

\section{ECR Business Activities}

Figure 2 illustrates the various ECR initiatives and shows that category management (59\%) and EDI (49\%), have the greatest number of respondents committed to their implementation, while cross-docking $(19 \%)$ and continuous replenishment $(23 \%)$ have the smallest number. Even though category management $(59 \%)$ is more widely used than the other initiatves, only $10 \%$ of respondents are committed to the implementation of this business activity as part of their ECR strategy. EDI (17.1\%) implementation as part of an ECR strategy has by far the greatest commitment in terms of ECR strategy, while activity-based costing (4\%) and cross-docking (5\%) have the lowest respondent commitment as part of their ECR strategy. These results suggest that although Australian grocery industry members are actively engaged in a number of the ECR initiatives, they view each activity on its own merit - and have, thus far at least, shown little interest in integrating their improved supply chain management practices into an holistic ECR approach. 


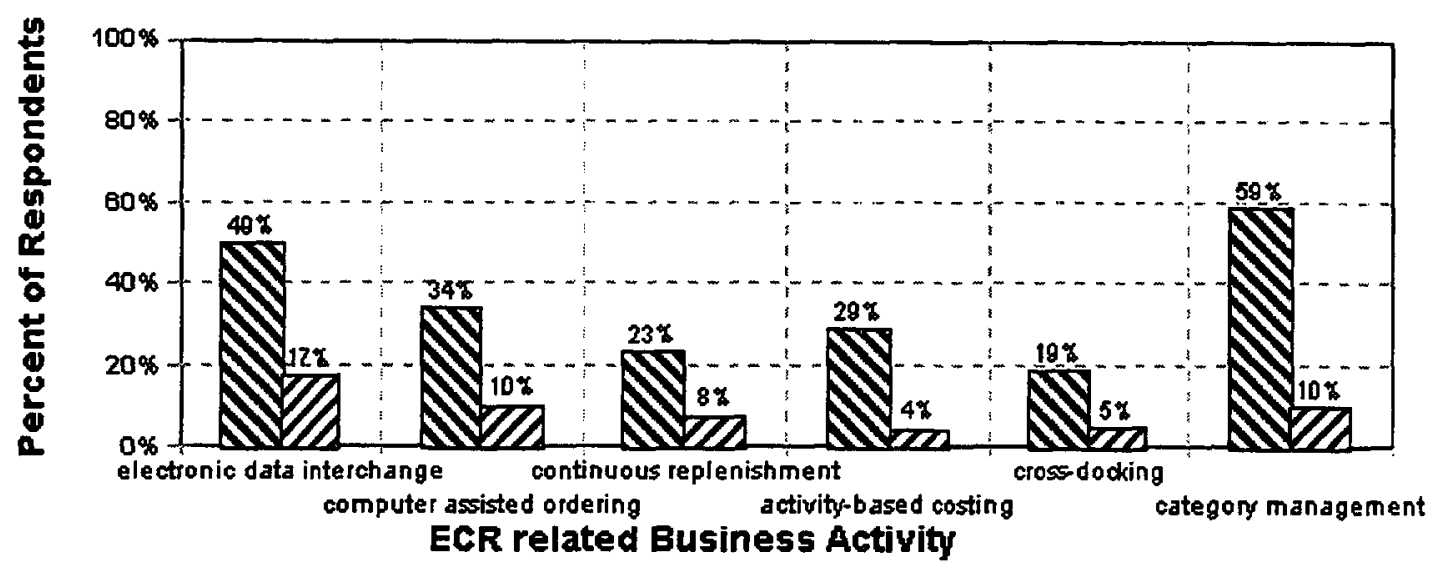

Committed to Implementation

Committed to Implementation (ECR)

\section{ECR Awareness}

Table 1 shows that just over two-thirds (61\%) of respondents were previously aware of the ECR strategy, while another third (34\%) were unaware of ECR before receiving this survey. Two-thirds of the group of 'aware' organisations are actively engaged in pursuing an ECR strategy and, in Table 2, we have summarised the reasons why these respondents are actively pursuing this strategy. This list makes it clear that the 'threat from alternative store formats' which motivates so many U.S. supermarkets is of little importance to Australian grocery industry members.

\begin{tabular}{|c|c|}
\hline ECR status & Percent \\
\hline Not Aware of ECR & $34 \%$ \\
\hline Aware of ECR: & $61 \%$ \\
\hline - Actively pursuing ECR & $40 \%$ \\
\hline - Not actively pursuing ECR & $16 \%$ \\
\hline - Unknown if actively pursuing ECR & $5 \%$ \\
\hline Other & $5 \%$ \\
\hline
\end{tabular}

Table 1. Respondents ECR status.

\begin{tabular}{|r|c|}
\hline \multicolumn{1}{|c|}{ Reason } & Percent \\
\hline \hline Improve efficiency of your organisation & $60 \%$ \\
\hline Pressure from trading partner(s & $46 \%$ \\
\hline Cost savings to your organisation & $45 \%$ \\
\hline Improve efficiency of overall supply chair & $45 \%$ \\
\hline Cost savings to overall supply chain & $33 \%$ \\
\hline Threats from alternative store format & $8 \%$ \\
\hline Othe & $6 \%$ \\
\hline
\end{tabular}

Table 2. Reasons for actively pursuing and ECR strategy.

Figure 3 summarises respondents' views of the likely benefits of ECR to the Australian grocery industry and shows that the majority of those respondents who are aware of ECR believe the Australian grocery supply chain can gain significant benefit from ECR in terms of improved efficiency (76\%) and reduced costs (61\%); and that the respondent's own organisation can benefit $(61 \%)$ from pursuing an ECR strategy. Of the total group of respondents, $47 \%$ believe that ECR will improve the efficiency of the grocery supply chain, while $37 \%$ of all respondents believe that ECR will remove costs from the supply chain and also benefit their own organisation. 


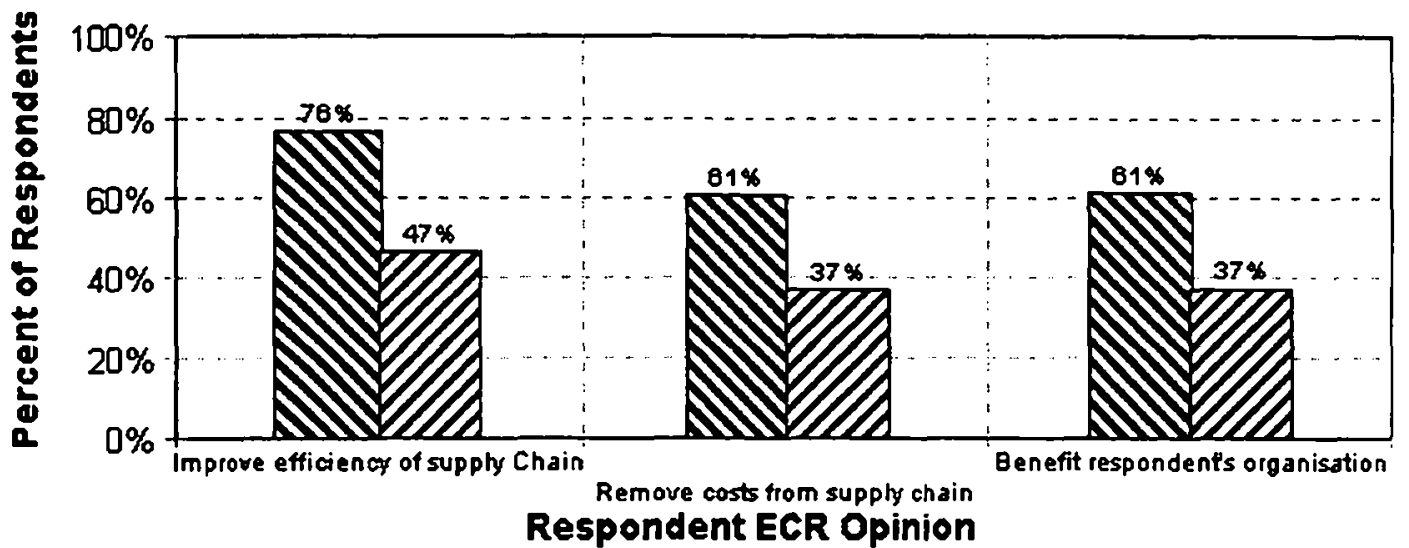

NDCR aware respondents (61\%) Ш

\section{DISCUSSION AND CONCLUSIONS}

Our research into ECR within Australia provides very strong evidence in two areas:

- that the inefficient business practices of deal selling/buying and forward buying (figure 1), which inadvertently push excessive inventory into the supply chain, exist within the Australian grocery industry although not necessarily to the same extent as in the U.S.

- that Australian organisations have begun implementing business activities and initiatives that are essential for the adoption of the ECR strategy.

These results suggest that the Australian grocery industry is a 'push system', like the U.S., where inventory is continually pushed into the supply chain by supplier deals, which in tum lead to forward buying by customers.

There is considerable interest in ECR in Australia, with $61 \%$ of respondents being aware of ECR and $40 \%$ of respondents actively pursing an ECR strategy (table 1). Despite this interest in ECR, we are concerned that there is no real commitment to its implementation. This is borne out by the fact that while $40 \%$ of respondents are actively pursuing an ECR strategy (table 1) only 17\% (EDI) and 4\% (ABC) respectively of respondents are actually committed to the implementation of the essential business activities (figure 2) necessary for the successful implementation of ECR.

A review of the Australian grocery industry (Commercial Economic Advisory Service of Australia 1991) identified inefficiencies within the Australian grocery industry which ECR seeks to address. This review even identified threats from alternative store formats which were likely to have an adverse effect on the traditional grocery store, the supermarket. Given the findings of this review, we find it somewhat surprising that respondents to our survey did not indicate threats from alternative store formats as a main reason for adopting ECR, and that there is not a stronger commitment to implement the necessary ECR business activities/initiatives.

One of the main reasons given for adopting ECR is pressure from trading partners (table 2). If organisations are pressured and/or coerced into using an ECR strategy we do not believe that they can be committed to its implementation and therefore gain the potential benefits from such implementation. These results, which differ significantly from the (comparatively limited) evidence available from the U.S. suggest that the Australian motive for engaging in ECR may well be quite different. Indeed, the likelihood is that Australian grocery industry members appear to be 'encouraged' to engage in ECR by large and powerful customers (supermarkets) - a situation which is reminiscent of the Australian experience with EDI. There is thus a real danger that, as with EDI, organisations may become involved only to the extent required by their larger and more powerful trading partners, so that the full benefits of a strategic approach may be lost.

The survey reported in this paper provides the first 'hard' evidence of Australian ECR activities and attitudes. One thing which has become clear from the results is that, as with all surveys (which provide a 'snap-shot' of a respondent group at a point in time) we have made some fascinating discoveries, but opened up some even more intriguing possibilities which the data cannot answer satisfactorily. The next step is clearly to engage in case studies of Australian and overseas organisations involved in ECR to discover whether our suspicions about the motivations for ECR involvement are correct. This project is being undertaken by another member of the Monash Electronic Commerce Research Group and our serendipitous discovery that the member nations of the European Union have nominated ECR as a major area of interest for the next few years encourages us to hope for an enthusiastic response from prospective case study participants. 


\section{REFERENCES}

Allvine, F. (1971). The future for trading stamps and games. Food Marketing and distribution. D. McLaughlin and C. Mallowe. New York, Chain Store Publishing Corporation, 169-183.

Anderson, B. (1996). The art and science of computer assisted ordering: methods for management. Westport, Connecticut, Quorum Books.

Brawn, D. (1989). EDI developments abroad and how they impact Australia. IDC Conference: EDI - The key to Profitability in the 1990s, Sydney, Australia, IDC Conferences.

Chain Store Age (1971). Behind the new wave discount super revolution. Food Marketing and Distribution. D. M. a. C. Mallowe. New York, Chain Store Publishing Corporation, 131-139.

Clark, T. (1994) Linking the Grocery Channel: Technological Innovation, Organizational Transformation, and Channel Performance, Harvard University: PhD thesis.

Commercial Economic Advisory Service of Australia (1991). Grocery Industry Review: June 1991. St Leonards, Commercial Economic Advisory Service of Australia.

Cooke, J. (1994). Logistics quality: Part III - Beyond quality ... speed. Traffic Management. 33(6), 32-37.

Cross, G. J. (1993). Continuous replenishment planning: An untapped gold mine. Transportation and Distribution. Dec. 34(12), 49.

deRoulet, D. G. (1993). ECR: Better information cuts costs. Transportation \& Distribution 34(10), 63.

Ellram, L. M., B. J. La Londe and M. M. Weber (1989). Retail Logistics. International Journal of Physical Distribution \& Materials Management. 19(12), 29-39.

Emmelhainz, M. (1990). Electronic Data Interchange: A total management guide. New York, Van Nostrand Reinhold.

Fensholt, C. (1992). Presenting the 1992 Supermarket Business Award for Excellence to Shaw's Supermarkets, Inc. Supermarket Business. 47(12), 23-25,81.

Forbes magazine (1971). The grocery business: Maybe the stockholders should be picketing instead. Food Marketing and distribution. D. McLaughlin and C. Mallowe. New York, Chain Store Publishing Corporation, 60-70.

Garry, M. (1992). How's Your Scan Data? Progressive-Grocer. 71(10), 83-90.

Garry, M. (1994a). A blueprint of the future. Progressive Grocer. 73(10), 63-66.

Garry, M. (1994b). Is there life after CRP? Progressive Grocer. 73(9), 73-78.

Garry, M. (1994c). The stepping stone to ECR. Progressive Grocer. 73(6), 59-60.

Garry, M. (1994d). Where's the beef. Progressive Grocer. 73(4).

Garry, M. (1995). Industry Snapshot. Progressive Grocer. 74(1), 11.

Gilmour, P. (1993). Integrated Logistics Management. Logistics Management: An Australian framework. P. Gilmour and R. Lansbury. London, Longman Cheshire, 3-51.

Gnau, K., T. Richardson, J. Dippold (1992). Nielson Category management: Positioning your organisation to win. Chicago, NTC Business Books/American Marketing Association.

Harding, P. (1995). Perspective: QR and ECR, Kurt Salmon Associates.

Hastings, P. (1994). Capabilities will supersede brands. Purchasing and Supply Management (Logistics Supplement Dec, 4-5.

Hayward, G. and G. York (1976). The food store distributor: A retail sales guide. New York, Chain Store Publications Corporation.

Hoban, T. (1993) Efficient Consumer Response (ECR): Perceived Barriers and Opportunities, Raleigh, North Carolina State University: PhD thesis.

Hofler, R. (1996). Glossary of Grocery Industry Terms. Stamford, Progressive Grocer Associates.

Klima, G. (1993). EDI at supervalu "Past - Present - Future". The Sixth Intermational Conference Electronic Data Interchange \& Interorganizational Systems, Bled, Slovenia.

Knill, B. (1990). Quick Response: Now for the Hard Part. Material Handling Engineering. 45(3), 67-78.

Kurt Salmon Associates (1993). Efficient Consumer Response: Enhancing Consumer Value in the Grocery Industry, American Meat Institute, Food Marketing Institute, Grocery Manufacturers of America, National Food Brokers Association, Uniform Code Council.

Liesse, J. (1994). The nitty-gritty of ECR systems: How one company makes it pay. Advertising Age. 65(19), S-1.

Mathews, R. (1995a). The power of category management. Progressive Grocer. 74(8), 12-14.

Mathews, R. (1995b). Spartan pulls the plug on VMI. Progressive Grocer. 74(11), 64-65.

Mayo, J. (1993). The American Grocery Store: The business evolution of an architectural space. Westport, Greenwood Press. 
McKinsey \& Co. (1992). Evaluating the impact of alternative store formats. Chicago, Supermarket Industry Convention, Food Marketing Institute.

Michelson, P. (1995). The emerging shape of retail logistics. Managing Retail Logistics Conference, Melbourne, Australia, IBC Conferences Pty Ltd.

Miller, J. (1996). Implementing activity-based management in daily operations. New York, John Wiley \& Sons.

Morgenstein, M. and H. Strongin (1992). Modern retailing: management principles and practices. Englewood Cliffs, Regents/Prentice Hall.

National Commission of Food Marketing (1971). Private branding by retailers. Food Marketing and distribution. D. McLaughlin and C. Mallowe. New York, Chain Store Publishing Corporation, 151161.

Newton, D. J. (1993). Nontraditional retailers challenge the supermarket industry. FoodReview. 16(1), $2-7$.

Peak, H. and E. Peak (1977). Supermarket merchandising and management. Englewood Cliffs, Prentice-Hall.

Pintel, G. and J. Diamond (1991). Retailing. Englewood Cliffs, Prentice-Hall.

Porter, M. (1979). How Competative forces shape strategy. Harvard Business Review. March-April, 137-145.

Porter, M. (1985). Competative advantage: creating and sustaining superior performance. New York, The Free Press.

Retail World Pty Ltd (1995). Grocery industry marketing guide 1995. Rozelle, Retail World Pty Ltd.

Robins, G. (1994). Sailing into ECR's uncharted waters. Stores. 76(10), 43-44.

Sansolo, M. (1993). ECR. Progressive Grocer. 72(11), 47-50.

Sansolo, M. (1994). Consumer spending shrinks. Progressive Grocer: 61st Annual Report of The grocery Industry. 73(4), 11.

Sansolo, M. and M. Garry (1992). Buyer/Seller Relations: The Rumors of Peace Remain Unfounded - 59th

Annual Report of the Grocery Industry. Progressive Grocer Supplement. 71(4), 24-26.

Schlossberg, H. (1992). Grocers Seek Peace Treaty in War with Manufacturers. Marketing News. 26(12), 1617.

Smith, K. (1993). No brand too small. Progressive Grocer. 72(12), SS4-SS5.

Spence, M. A. (1994). EDI quickly becoming the norm. CMA Magazine. 68(5), 14-16.

Swatman, P. (1993). Integrating EDI into Existing Organisational Structure and Internal Application

Systems: the Australian Experience. School of Computing., Curtin University, PhD Thesis.

Teinowitz, I. (1993). Grocery trade deals set to enter new era. Advertising Age. 64(21), 3.

Thayer, W. (1991). Computer-Aided Ordering Is Ready ... Should You Care? Progressive Grocer. 70(3), 8186.

Weinstein, S. (1993). On the path to better selling. Progressive Grocer. 72(11), 54-55.

Weinstein, S. (1995). On the cutting edge. Progressive Grocer. 74(8), 34-40.

White, M., E. Craig, E. Wiland, et al. (1995). The Food Week industry yearbook and directory of suppliers 1995 edition Sydney, lan Huntley Pty Ltd.

Wood, P. K. (1996). Preparing for ECR at the store level. Chain Store Age. 72(5), 230.

Weinstein, S. (1993). On the path to better selling. Progressive Grocer 72(11), 54-55.

Weinstein, S. (1995). On the cutting edge. Progressive Grocer 74(8), 34-40.

White, M., E. Craig, E. Wiland, et al. (1995). The Food Week industry yearbook and directory of suppliers 1995 edition. Sydney, lan Huntley Pty Ltd.

Wood, P. K. (1996). Preparing for ECR at the store level. Chain Store Age 72(5), 230. 